\title{
Kra-Dai Language
}

National Cancer Institute

\section{Source}

National Cancer Institute. Kra-Dai Language. NCI Thesaurus. Code C161910.

A language family of tonal languages found in southern China, Northeast India and Southeast Asia. 